\title{
Development and Validation of a HPLC and an UV Spectrophotometric Methods for Determination of Dexibuprofen in Pharmaceutical Preparations
}

\author{
Selvadurai Muralidharan and Subramania Nainar Meyyanathan \\ Department of Pharmaceutical Analysis, JSS College of Pharmacy, Ootacamund, Tamilnadu-643 001, India
}

Correspondence should be addressed to Selvadurai Muralidharan, muraliaimst@gmail.com

Received 12 April 2011; Accepted 16 May 2011

Academic Editors: G. N. C. Chiu and F. de la Calle

Copyright ( $) 2011$ S. Muralidharan and S. N. Meyyanathan. This is an open access article distributed under the Creative Commons Attribution License, which permits unrestricted use, distribution, and reproduction in any medium, provided the original work is properly cited.

\begin{abstract}
A high-performance liquid chromatographic (HPLC) and a ultraviolet (UV) methods were developed and validated for the quantitative determination of Dexibuprofen (DI) in pharmaceutical dosage form. HPLC was carried out by reversed phase technique on a RP-18 column with a mobile phase composed of acetonitrile and $0.5 \%$ triethylamine ( $\mathrm{pH} 7.5$ adjusted with orthophosphoric acid $(30: 70, \mathrm{v} / \mathrm{v}))$. UV method was performed with the $\lambda$ max at $222.0 \mathrm{~nm}$. Both the methods showed good linearity, reproducibility and precision. No spectral or chromatographic interferences from the tablet excipients were found in UV and HPLC. The method was successfully applied to commercial DEXIFEN tablets. Validation parameters such as linearity, precision, accuracy, and specificity were determined. The proposed method could be applicable for routine analysis of DI and monitoring of the quality of marketed drugs.
\end{abstract}

\section{Introduction}

Nonsteroidal anti-inflammatory drugs (NSAIDs) like \pm ibuprofen are effective for the relief of pain, and their use is widespread [1-3]. \pm ibuprofen, which contains equal quantities of (+) Ibuprofen and (-) Ibuprofen, has been used as an anti-inflammatory and analgesic agent for over 30 years. (+) Ibuprofen, or Dexibuprofen, is the pharmacologically effective enantiomer of + ibuprofen [1-3]. The present UV and HPLC methods are relatively simple, rapid, and highly sensitive in the determination of dexibuprofen.

Only limited methods have been reported in the literature survey [4-10]. The aim of the present work was to develop and validate a simple, fast, and reliable isocratic RPHPLC and UV method for the determination of DI in pharmaceutical dosage forms. The important features and novelty of the proposed method included simple sample treatment with sonication of small amount of powder sample at ambient temperature, centrifugation, and dilution; short elution time with internal standard eluted prior to DI; good precision (R.S.D. less than 5\%) and high recovery (greater than
95\%). Confirmation of the applicability of the developed method was validated according to the International Conference on Harmonisation (ICH), to determination of DI in pharmaceutical dosage forms.

\section{Experimental}

2.1. Chemicals. HPLC grade acetonitrile (ACN) and triethylamine (A.R. grade) were purchased from Qualigens Fine Chemicals, Mumbai. Water HPLC grade was obtained from a Milli-QRO water purification system. Dexibuprofen standard and ibuprofen (Internal standard) were provided by Noven Life Sciences Private Limited, Hyderabad, India.

2.2. Instrumentation and Analytical Conditions. HPLC chromatographic separation was performed on a Shimadzu liquid chromatographic system equipped with a LC-10ATvp solvent delivery system (pump), SPD M-10AVP photo diode array detector, and Rheodyne $7725 \mathrm{i}$ injector with $50 \mu \mathrm{L}$ loop volume. Class-VP 6.01 data station was applied 
for data collecting and processing (Shimadzu, Japan). The HPLC was carried out at a flow rate of $1.0 \mathrm{~mL} \mathrm{~min}^{-1}$ using a mobile that is phase constituted of acetonitrile- $50 \mathrm{mM}$ potassium dihydrogen orthophosphate ( $\mathrm{pH} 7.5$ adjusted with orthophosphoric acid $(45: 55, \mathrm{v} / \mathrm{v}))$, and detection was made at $222.0 \mathrm{~nm}$. The mobile phase was prepared daily, filtered through a $0.45 \mu \mathrm{m}$ membrane filter (Millipore) and sonicated before use. A Princeton SPHER C 18 column $(25 \mathrm{~cm}$ $\times 4.6 \mathrm{~mm}$ i.d., $5 \mu$ ) was used for the separation. UV method was performed on a UV-VISIBLE spectrophotometer, UV160 (Shimadzu) with the $\lambda$ at $222.0 \mathrm{~nm}$ and using $1.0 \mathrm{~cm}$ quartz cell.

\subsection{Preparation of Standard Solutions}

2.3.1. HPLC Method. For the calibration curve, accurately weighed $100.0 \mathrm{mg}$ of DI was transferred to a $100 \mathrm{~mL}$ volumetric flask and dissolved in a mixture of water and methanol of the ratio $1: 1 \mathrm{v} / \mathrm{v}$. From this solution, other solutions with concentrations of 10.0, 20.0,30.0,40.0, 50.0, and $60.0 \mu \mathrm{g} \mathrm{mL}^{-1}$ were obtained by diluting adequate amounts in triplicate.

2.3.2. UV Method. For the calibration curve, accurately weighed $100.0 \mathrm{mg}$ of DI was transferred to a $100 \mathrm{~mL}$ volumetric flask and dissolved in a mixture of water and methanol of the ratio $1: 1 \mathrm{v} / \mathrm{v}$. From this solution, other solutions with concentrations of 2.0, 4.0, 6.0, 8.0, 10.0, and $12.0 \mu \mathrm{g} \mathrm{mL}-1$ were obtained by diluting adequate amounts in triplicate.

\subsection{Preparation of Sample Solutions}

2.4.1. HPLC Method. Twenty tablets, each containing 200.0, 300.0 , and $400.0 \mathrm{mg}$ of DI were weighed and finely powdered; a quantity of powder equivalent to $20.0,30.0$ and $40.0 \mathrm{mg}$ of DI was weighed and transferred to a sintered glass crucible. To this $5.0 \mathrm{~mL}$ of $1.0 \mathrm{mg} \mathrm{mL}^{-1}$ solution of ibuprofen was added and the drugs were extracted with three quantities, each of $20 \mathrm{~mL}$ of mixture of methanol and water $(1: 1 \mathrm{v} / \mathrm{v})$. The combined extracts were made up to $100 \mathrm{~mL}$ with mobile phase, and further dilutions were made to get a concentration of $20.0,30.0$, and $40.0 \mu \mathrm{g} / \mathrm{mL}$ of dexibuprofen, $50.0 \mu \mathrm{g} / \mathrm{mL}$ of Ibuprofen as internal standard, and this solution was used for the estimation.

2.4.2. UV Method. Accurately weighed amount of powder equivalent to $20.0,30.0$, and $40.0 \mathrm{mg}$ of DI was transferred to $100 \mathrm{~mL}$ volumetric flask and dissolved in the mobile phase to obtain a concentration of $20.0,30.0$, and $40.0 \mu \mathrm{g} \mathrm{mL}^{-1}$. An aliquot of this solution was diluted in mobile phase to obtain a solution with final concentration of $4.0 \mu \mathrm{g} \mathrm{mL}{ }^{-1}$.

2.5. Method Validation. The objective of method validation is to demonstrate that the method is suitable for its intended purpose as it is stated in ICH guidelines [11]. The method was validated for linearity, precision (repeatability and intermediate precision), accuracy specificity, short-term stability, and system suitability. Standard plots were constructed with six concentrations in the range of $10-60 \mu \mathrm{g} \mathrm{mL}^{-1}$ prepared in triplicates to test linearity. The ratio of peak area signal of DI to that of IS was plotted against the corresponding concentration to obtain the calibration graph. The linearity was evaluated by linear regression analysis that was calculated by the least square regression method. The precision of the assay was studied with respect to both repeatability and intermediate precision. Repeatability was calculated from six replicate injections of freshly prepared DI solution in the same equipment at a concentration $50 \mu \mathrm{g} \mathrm{mL}^{-1}$ of the intended test concentration value on the same day. The experiment was repeated by assaying freshly prepared solution at the same concentration additionally on two consecutive days to determine intermediate precision. Peak area ratio of DI to that of IS was determined and precision was reported as \% R.S.D. Method accuracy was tested (\% recovery and $\%$ R.S.D. of individual measurements) by analysing samples of DI at three different levels in pure solutions using three preparations for each level. The results were expressed as the percentage of DI recovered in the samples. Specificity was assessed by comparing the chromatograms obtained from sample of pharmaceutical preparation and standard solution with those obtained from excipients which take part in the commercial tablets and verifying the absence of interferences. Sample solution short-term stability was tested at ambient temperature $\left(20 \pm 1^{\circ} \mathrm{C}\right)$ for three days. In order to confirm the stability of both standard solutions at $100 \%$ level and tablets sample solutions, both solutions protected from light were reinjected after 24 and $48 \mathrm{~h}$ at ambient temperature and compared with freshly prepared solutions. A system suitability test was performed by six replicate injections of the standard solution at a concentration of $50 \mu \mathrm{g} \mathrm{mL}^{-1}$ verifying IS/DI resolution $>2$, \% R.S.D. of peak area ratios of DI to that of IS $\pm 2 \%, \%$ R.S.D. of each peak retention time $\pm 2 \%$.

\section{Results and Discussion}

\subsection{Validation of Methods}

3.1.1. Linearity. Six point calibration graphs were constructed covering a concentration range of $10-60 \mathrm{mg} \mathrm{mL}^{-1}$. Three independent determinations were performed at each concentration. Linear relationships between the ratio of the peak area signal of DI to that of IS versus the corresponding drug concentration were observed, as shown by the results presented in Table 1. The standard deviations of the slope and intercept were low. The determination coefficient $\left(r^{2}\right)$ exceeded 0.99 (Figure 2).

3.1.2. Precision. The carried out repeatability study $(n=6)$ showed a R.S.D. of $0.858 \%$ for the peak area ratios of DI to that of IS obtained, thus showing that the equipment used for the study worked correctly for the developed analytical method and is highly repetitive. For the intermediate precision, a study carried out by the same analyst working on 
TABLE 1: Results of regression analysis of data for the quantitative determination of dexibuprofen by the proposed methods.

\begin{tabular}{lcc}
\hline Statistical parameters & HPLC & UV \\
\hline Concentration range $\left(\mu \mathrm{g} \mathrm{mL}^{-1}\right)$ & $10-60$ & $2-12$ \\
Regression equation & $y=0.0186 x+0.044$ & $y=0.1117+0.0095$ \\
Correlation coefficient $(r)$ & 0.9915 & 0.9973 \\
\hline
\end{tabular}

TABle 2: Accuracy study for Dexibuprofen $(n=5)$.

\begin{tabular}{lccrrr}
\hline \multirow{2}{*}{ Nominal concentration $\mu \mathrm{g} \mathrm{mL}^{-1}$ (HPLC) } & \multirow{2}{*}{ Nominal concentration $\mu \mathrm{g} \mathrm{mL}^{-1}$ (UV) } & \multicolumn{2}{c}{ Mean recovery (\%) } & \multicolumn{2}{c}{ R.S.D. (\%) } \\
& & HPLC & UV & HPLC & UV \\
\hline 10.00 & 2.0 & 2.30 & 1.91 & 0.32 & 0.12 \\
30.00 & 6.0 & 28.24 & 6.05 & 0.78 & 0.35 \\
60.00 & 12.0 & 57.99 & 11.68 & 1.02 & 0.62 \\
\hline
\end{tabular}

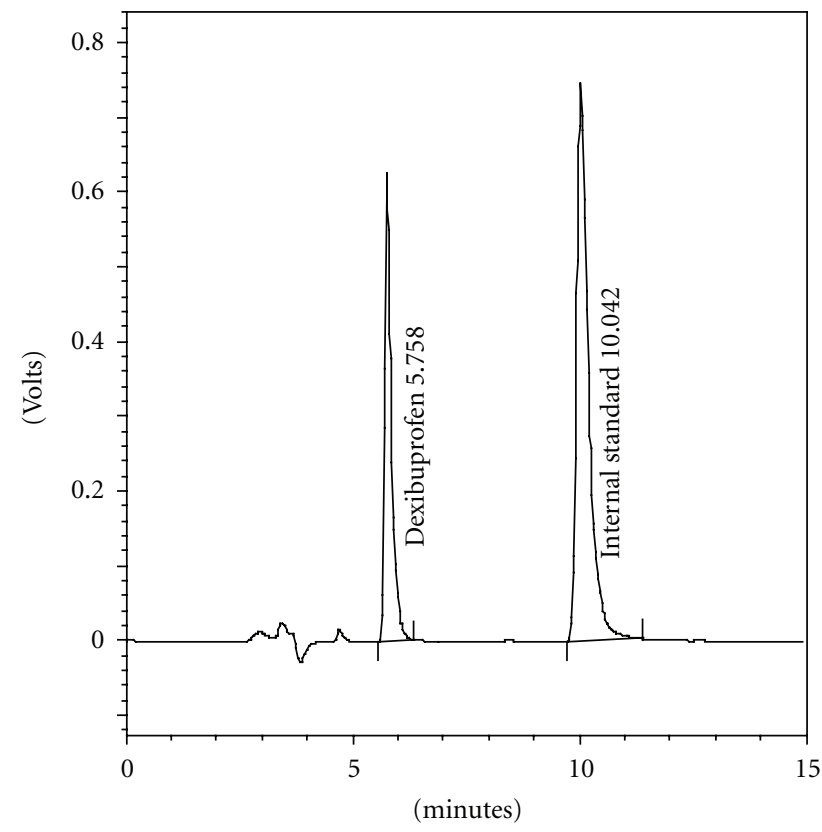

FIGURE 1: Typical sample chromatogram of dexibuprofen and internal standard.

TABLE 3: System suitability study (HPLC).

\begin{tabular}{lcc}
\hline Retention time $(\mathrm{min})$ & DI $(50 \mu \mathrm{g} / \mathrm{mL})$ & IS $(10 \mu \mathrm{g} / \mathrm{mL})$ \\
\hline Mean $(n=5)$ & 7.53 & 11.12 \\
\% R.S.D. & 0.39 & 0.13 \\
\hline
\end{tabular}

two consecutive days $(n=3)$ indicated a R.S.D. of $0.744 \%$. Both values were far below $5 \%$, the limit percentage set for the precision, and indicated a good method precision.

3.1.3. Accuracy. The data for accuracy were expressed in terms of percentage recoveries of DI in the real samples. These results are summarized in Table 2. The mean recovery data of DI in real sample were within the range of 100.01 and $102.28 \%$, and mean \% R.S.D. was $1.04 \%$, satisfying the acceptance criteria for the study.

3.1.4. Specificity. The HPLC chromatogram recorded for the mixture of the drug excipients revealed no peak within a re-

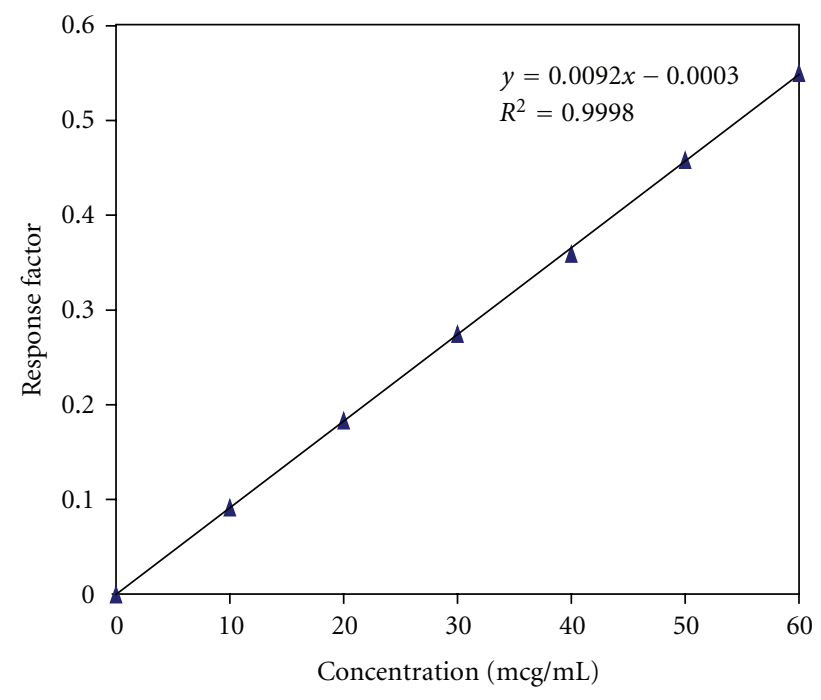

Figure 2: Calibration curve of dexibuprofen.

tention time range of $5 \mathrm{~min}$. The results showed that the developed method was specific as none of the excipients interfered with the analytes of interest (Figure 1).

3.1.5. Stability. The stability of DI in standard and sample solutions containing IS was determined by storing the solutions at ambient temperature $\left(20 \pm 1^{\circ} \mathrm{C}\right)$ protected from light. The solutions were checked in triplicate after three successive days of storage, and the data were compared with freshly prepared samples. In each case, it could be noticed that solutions were stable for $72 \mathrm{~h}$, as during this time the results did not decrease below $97 \%$. This denotes that DI is stable in standard and sample solutions for at least 3 days at ambient temperature, protected from light, and is compatible with IS.

3.1.6. System Suitability. The resolution factor between IS and DI, in the developed method, was above 2. The \% R.S.D. of peak area ratio of DI to that of IS and retention times for both drug and IS were within $2 \%$ indicating the suitability of the system (Table 3 ). These results indicate the applicability 
TABLE 4: Results obtained for determination of dexibuprofen in SIBET marketed formulations.

\begin{tabular}{|c|c|c|c|c|c|c|}
\hline \multirow{3}{*}{ Drug } & \multicolumn{2}{|c|}{ HPLC } & \multicolumn{2}{|c|}{ UV } & HPLC & \multirow[t]{2}{*}{ UV } \\
\hline & \multicolumn{2}{|c|}{ Amount mg/tab } & \multicolumn{2}{|c|}{ Amount mg/tab } & \multirow{2}{*}{\multicolumn{2}{|c|}{ \% Recovery }} \\
\hline & Labelled & Found & Labelled & Found & & \\
\hline \multirow{3}{*}{ Dexibuprofen } & 400 & 385.23 & 400 & 378.89 & 96.30 & 95.89 \\
\hline & 300 & 291.98 & 300 & 285.67 & 97.32 & 93.12 \\
\hline & 200 & 189.83 & 200 & 185.42 & 94.91 & 92.05 \\
\hline
\end{tabular}

of this method to routine with no problems, with its suitability being proved. The statistical evaluation of the proposed method revealed its good linearity, reproducibility, and its validation for different parameters and led us to the conclusion that it could be used for the rapid and reliable determination of DI in pharmaceutical forms.

3.1.7. Assay of Tablets. The validated method was applied for the assay of commercial tablets containing $200 \mathrm{mg}, 300 \mathrm{mg}$, and $400 \mathrm{mg}$ of DI (DEXIFEN); each sample was analysed in triplicate after extracting the drug as mentioned in the assay sample preparation of Section 2 and injections were carried out in triplicate. Figure 1 shows an HPLC chromatogram of DI in pharmaceutical tablets. None of the tablets ingredients interfered with the analyte peak. The results presented in Table 4 are in good agreement with the labelled content.

\section{Conclusion}

A validated isocratic HPLC and UV methods has been developed for the determination of DI in dosage forms. The proposed method is simple, rapid, accurate, precise, and specific. Its chromatographic run time of $10.5 \mathrm{~min}$ allows the analysis of a large number of samples in a short period of time. Therefore, it is suitable for the routine analysis of DI in pharmaceutical dosage forms. The simplicity of the method allows for application in laboratories that lack sophisticated analytical instruments such as LC-MS/MS or GC-MS/MS that are complicated, costly, and time consuming rather than a simple HPLC-UV method. Considering the possible worldwide development of counterfeit DEXIFEN, the proposed method could be useful for the national quality control laboratories in developing countries.

\section{References}

[1] R. A. Dionne and L. McCullagh, "Enhanced analgesia and suppression of plasma $\beta$-endorphin by the $S(+)$-isomer of ibuprofen," Clinical Pharmacology and Therapeutics, vol. 63, no. 6, pp. 694-701, 1998.

[2] A. M. Evans, "Enantioselective pharmacodynamics and pharmacokinetics of chiral non-steroidal anti-inflammatory drugs," European Journal of Clinical Pharmacology, vol. 42, no. 3, pp. 237-256, 1992.

[3] K. D. Rainsford, Pharmacology and Toxicology of Ibuprofen, Taylor \& Francis, London, UK, 1999.

[4] A. D. Hulst, P. Augustijns, S. Arens et al., "Determination of artesunate by capillary electrophoresis with low UV detection and possible applications to analogues," Journal of Chromatographic Science, vol. 34, no. 6, pp. 276-281, 1996.

[5] J. Krzek, M. Starek, and D. Jelonkiewicz, "RP-TLC determination of $\mathrm{S}(+)$ and $\mathrm{R}(-)$ ibuprofen in drugs with the application of chiral mobile phase and UV densitometric detection," Chromatographia, vol. 62, no. 11-12, pp. 653-657, 2005.

[6] P. D. Sethi, Identification of Drugs in Pharmaceutical Formulations by Thin Layer Chromatography, CBS Publisher, New Delhi, India, 1992.

[7] C. J. T. Thomas and S. Savage, "High-performance liquid chromatographic determination of ibuprofen in bulk drug and tablets," Drug Development and Industrial Pharmacy, vol. 11, no. 5, pp. 1123-1131, 1985.

[8] Y. Y. Lau, "Determination of ibuprofen enantiomers in human plasma by derivatization and high performance liquid chromatography with fluorescence detection," Journal of Liquid Chromatography and Related Technologies, vol. 19, no. 13, pp. 2143-2153, 1996.

[9] H. Thomas Karnes, K. Rajasekharaiah, E. Ralph Small, and D. Farthing, "Automated solid phase extraction and hplc analysis of ibuprofen in plasma," Journal of Liquid Chromatography and Related Technologies, vol. 11, no. 2, pp. 489-499, 1988.

[10] U. Mandal, A. Das, S. Agarwal et al., "Bioequivalence study of two formulations containing $400 \mathrm{mg}$ dexibuprofen in healthy Indian subjects," Arzneimittel-Forschung, vol. 58, no. 7, pp. 342-347, 2008.

[11] "Q2A text on validation of analytical procedures," in Proceedings of the International Conference on Harmonization ( $\mathrm{ICH}$ '94), 1994. 

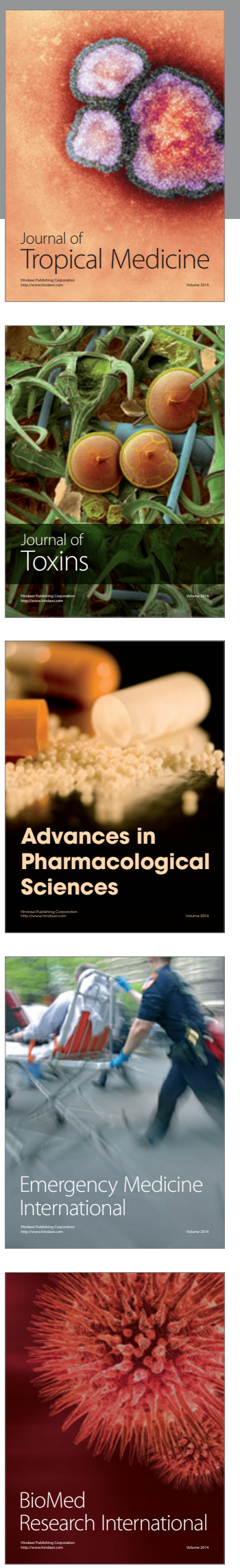
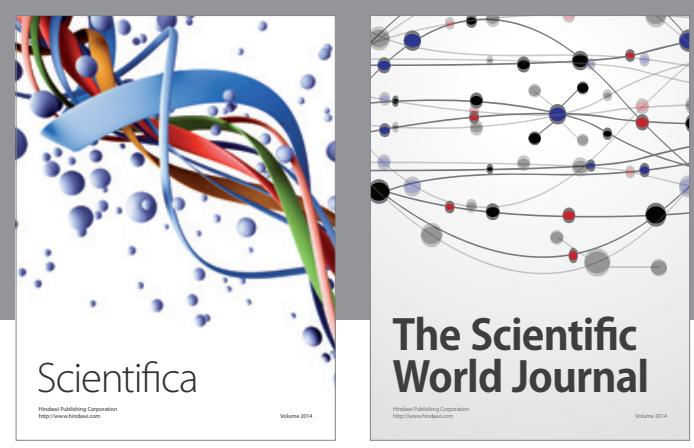

The Scientific World Journal
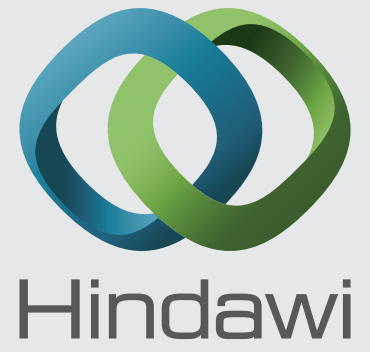

Submit your manuscripts at

http://www.hindawi.com
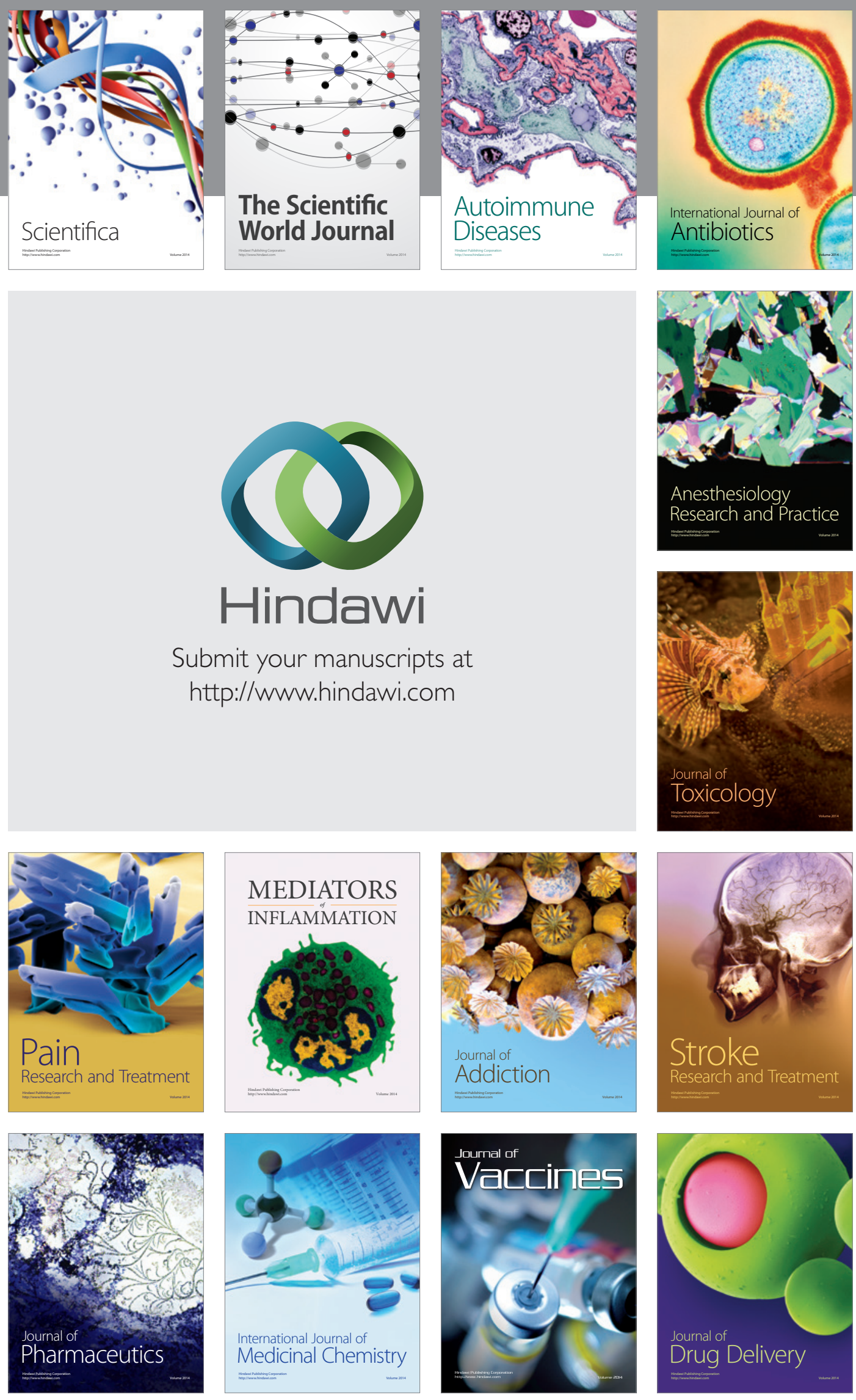